\title{
RELEVÂNCIA DO BRINCAR NA EDUCAÇÃO INFANTIL: CONSTITUINDO AUTONOMIA E IDENTIDADE DA CRIANÇA
}

\author{
Leonardo Augusto Castelhano Teixeira ${ }^{1}$
}

RESUMO: Neste artigo, entende-se que o tema apresentado como proposta para este projeto de Trabalho de Conclusão de Curso (TCC) intitulado " relevância do brincar na Educação Infantil: constituindo autonomia e identidade da criança" ocupa proeminentemente posição no contexto educacional que abarca o ciclo da Educação Básica Brasileira, devido ao fato de nos últimos anos ela estar sendo continuadamente submetida a diversas adaptações para ser ajustada de tal modo que possa atender plenamente às novas demandas sociais que têm surgido com o passar do tempo. Este tema articula-se à linha de pesquisa do curso de Pós-Graduação em Educação Infantil na Unimes que sugere investigar "o brincar, enquanto instrumento pedagógico". Neste sentido, restringe-se a explorar, contudo sem esgotar o assunto pertinente à significância da ação de brincar, dos jogos, das brincadeiras, dos brinquedos e da ludicidade na Educação Infantil (EI) atual, reconhecendo estes elementos como facilitadores do crescimento integral, $\mathrm{da}$ aprendizagem e da expansão das oportunidades da criança quanto: ao comunicar-se, ao experimentar novas vivências; ao aprimorar sua criatividade; ao socializar-se; ao integrarse e ao assimilar conhecimentos que, por conseguinte, a ajudarão a adquirir sua autonomia, formar a sua personalidade e posicionar-se como indivíduo, como preveem por exemplo, a Constituição Federal do Brasil, de 1988, o Plano Nacional de Educação (PNE), a Lei de Diretrizes e Bases da Educação Nacional (LDB) e as Diretrizes Curriculares Nacionais (DCNs).

Palavras-Chave: Educação. Lúdico. Brincar. Autonomia. Criança.

ABSTRACT: In this article, it is understood that the theme presented as a proposal for this project of Course Completion Work (TCC) entitled "relevance of play in Early Childhood Education: constituting autonomy and identity of the child" occupies a prominent position in the educational context that covers the cycle of Brazilian Basic Education, due to the fact that in recent years it is being continuously subjected to various adaptations to be adjusted so that it can fully meet the new social demands that have emerged over time.

This theme is articulated to the research line of the Post-Graduation course in Early Childhood Education at Unimes that suggests to investigate "playing as a pedagogical

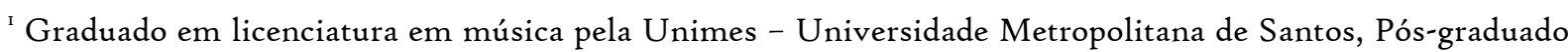
em Educação Infantil pela Unimes, Pós-graduado em Educação Musical pela Faveni - Faculdade Venda Nova do Imigrante, Pós-graduado em regência de coral com capacitação para docência pela Facuminas. Email: leonardocastelhano@yahoo.com.br.
} 
instrument". In this sense, it is restricted to explore, however without exhausting the subject pertinent to the significance of the action of playing, games, games, toys and playfulness in current Early Childhood Education (ECE), recognizing these elements as facilitators of integral growth, learning, and expansion of the child's opportunities as: to communicate, to experience new experiences; to enhance their creativity; to socialize; to integrate and assimilate knowledge that, consequently, will help them acquire their autonomy, form their personality and position themselves as individuals, as provided for example by the 1988 Federal Constitution of Brazil, the National Education Plan (PNE), the Law of Directives and Bases of National Education (LDB) and the National Curriculum Guidelines (DCNs).

Keywords: Education. Play. Autonomy. Child.

\section{INTRODUÇÃO}

Justifica-se este artigo como uma ação de grande valor para a ampliação do saber, onde, através das concepções de consagrados autores e da legislação concernente ao assunto, buscar-se-á evidenciar a relevância do brincar na EI para a formação da criança, quanto à constituição da sua autonomia e da sua identidade. Todavia, reconhecendo-se a pré-escola como o primeiro nível da Educação Básica brasileira, buscar-se-á contribuir para o acréscimo do conhecimento dos docentes da EI e de quaisquer leitores interessados pelo tema, permitindo-lhes contatar a importância dos jogos na fase pré-escolar e possibilitar ao docente deste ciclo educacional, refletir sobre a necessidade de ampliar seu saber de modo contínuo para efetivar acertadamente a intervenção pedagógica.

\section{Problema}

O brincar é de fato um fato imprescindível para a formação global da criança na

\section{Objetivos}

\section{I Objetivo Geral}

Verificar como o brincar contribui para a formação da autonomia e da identidade da criança;

\subsection{Objetivos Específicos}

$\checkmark$ Conceituar os temas: jogo, brincadeira, brinquedo e lúdico;

$\checkmark$ Destacar o que a legislação prevê sobre a ludicidade na EI; 
$\checkmark$ Discorrer sobre a importância da Psicomotricidade na EI.

\section{Metodologia}

Seguindo o aconselhamento de Marconi e Lakatos (2019) desenvolve-se esta pesquisa de revisão bibliográfica, caracterizada como pesquisa qualitativa, para conhecer novos saberes pelo estudo dos conteúdos encerrados em artigos científicos, livros, dicionários, Leis ou em outras fontes seguras da internet. Além do mais, pode-se classificála qualitativa, pois os dados que a compõem foram reunidos e apreciados de modo subjetivo pelo pesquisador, como propõe Appolinário (20II).

\section{$5 \mathrm{O}$ brincar, a ludicidade e a psicomotricidade: fatores essenciais para o desenvolvimento global da criança.}

\section{I Conceptualização de infância}

Para contextualizar o tema abordado julga-se oportuno recordar a etimologia e a definição da palavra infância. Quanto à sua origem verifica-se que este vocabulário

[...] vem do latim "in", que significa não e "fancia" que significa capacidade de fala. Dessa forma, a infância é caracterizada pela ausência da fala e a presença de comportamentos irracionais. A infância se contrapõe à vida adulta, pois estes comportamentos irracionais se desenvolvem no indivíduo adulto, providos de razão (LIMA, 2009 apud FARIA e COSTA, 2016, p.3)

Segundo o dicionário online de Português, infância é um substantivo feminino que limita o "período da vida humana desde o nascimento até cerca de 12 anos" (INFÂNCIA, 2020) e, consoante o Art. $2^{\circ}$ do Estatuto da Criança e do Adolescente, Lei n. 8.069, de 13 de julho de 1990, para todos os fins legais a idade exata deste período é "[...] até doze anos de idade incompletos" (BRASIL, 1990, s.p).

Sobre a importância da infância para a pessoa ratifica-se que o processo ligado a prática da cidadania é de valor inestimável para toda a sua vida e que ele se inicia na infância a partir do oferecimento de possibilidades de escolhas à criança que lhe permitem adquirir a sua autonomia (BRASIL, 1998b).

Acerca dos aspectos sociológicos da infância, evidencia-se que as ações sociais da criança são para ela elementos constituidores e que, por isto, compete à creche organizar o 
tempo e o espaço de modo padronizado e disponibilizar a devida dedicação e cuidados físicos à criança, como a alimentação, o sono e o banho, contudo, sempre zelando para que estes não sejam realizados de modo mecanizado e nem ignorem a importância que a relação professor-criança, que ocorre durante este cuidar, tem para ela (COUTINHO, 2oro apud GUIMARAES e ARENARI, 2018).

Assim, acrescenta-se que o processo relacionado ao desenvolvimento total da criança:

[...] depende tanto dos cuidados relacionais que envolvem a dimensão afetiva e dos cuidados com os aspectos biológicos do corpo, como a qualidade da alimentação e dos cuidados com a saúde, quanto da forma como esses cuidados são oferecidos e das oportunidades de acesso a conhecimento variados (BRASIL, 1998a, p.24)

Coutinho (2010 apud GUIMARAES e ARENARI, 2018, p. 3) realça “[...] como aspectos relevantes a serem observados pelo professor: os movimentos de reprodução/produção das crianças, as relações entre brincadeira/trabalho, o desafio de aprender a 'ver as crianças' [...]". Verifica-se, pois, ser competência do professor da EI: organizar, sistematizar e conduzir a criança ao experimentar situações de aprendizagem (BRASIL, 1998b).

No tópico a seguir discute-se a evolução infantil na primeira infância, ou seja, dos dois aos quatro anos e na idade pré-escolar, dos quatro aos seis anos de idade.

\subsection{O Desenvolvimento da criança entre dois e seis anos de idade.}

Gallahue, Ozmun e Goodway (2013) afirmam que na faixa etária dos dois aos seis anos a criança enquanto não está comendo, dormindo ou se dedicando a satisfazer os desejos dos adultos com quem convive, ela mantém foco no brincar, cuja importância assemelha-se àquela que o trabalho tem para o adulto e destacam que "[...] o brincar [...] é um importante facilitador do crescimento cognitivo e efetivo da criança mais nova, assim como importante recurso para o desenvolvimento tanto das habilidades amplas quanto das finas" (GALLAHUE, AZMUN e GOODWAY, 2013, p · 192-193).

Pode-se então inferir que a criança neste período se conserva em atividade ininterrupta que permite aumentar suas habilidades cognitivas que possibilitam-lhe 
construir a base para desenvolver seu pensamento lógico que ajudará a formular vaiados conceitos. Gallahue, Ozmun e Goodway (2013, p. 193, grifo dos autores) destacam que esta fase da vida infantil foi denominada por Piaget como “[...] estágio do pensamento préoperacional".

No $3^{\circ}$ vol. Do Referencial Curricular Nacional para a (RCNEI) evidencia-se que o movimento, os gestos, as brincadeiras de faz de conta e os jogos, entre outros, são elementos próprios da infância e que o

[...] brincar de roda, ciranda, pular corda, amarelinha etc, são maneiras de [o indivíduo infante] estabelecer contato consigo próprio e com o outro, de se sentir único e, ao mesmo tempo, parte de um grupo, e de trabalhar com as estruturas [...] em cada brinquedo (BRASIL, 1998c, p. 71).

Todavia, destaca-se que o pensamento da criança na faixa etária pré-escolar é contido pelas percepções que traduzem a sua capacidade de conhecer ou interpretar as mais variadas informações e que nesse processo ela organiza as novas informações que obtém com aquelas já assimiladas e gera um modelo de resposta adequadamente transformado (GALLAHUE, OZMUN e GOODWAY, 2013)

Não obstante Gallahuem, Ozmun e Goodway (2013, p. 298) afirmam que “[...] o desenvolvimento perceptivo-motor pode ser descrito como um processo de aquisição de maior habilidade e capacidade funcional, pelo uso de input sensorial, de integração sensorial, de interpretação motora, de ativação do movimento e de feedback [...]”

Sobre o desenvolvimento motor, Barbosa, Silveira e Oliveira (2014 apud FARIA e COSTA, 2016) afiançam que ele relaciona-se com as experiências externas e internas da pessoa iniciando no seu nascimento e durando por toda a sua vida sendo um fator único, individual e contínuo e que este aprimoramento psicomotor na pré-escola é um agente influenciador positivo nos atos do indivíduo consigo mesmo ou com o outro, "[...] através do domínio das capacidades psicofísicas, agindo de maneira consciente, planejada, lógica e crítica, de acordo com suas necessidades particulares" (BARBOSA, SILVEIRA e OLIVEIRA, 2014 apud FARIA e COSTA, 2016, p. 7)

Diante disto, ressalta-se que tudo que a criança experimenta exerce grande influência sobre ela. Embora na fase pré-escolar sua mente lógica não necessite de 
justificativas, ela simplesmente não consegue expressar sobre como chegou a uma determinada conclusão sobre algo e isto propicia-lhe "[...] uma multiplicidade de lugares e variáveis para promoção do crescimento cognitivo” (GALLAHUE, OZMUN e GOODWAY, 2013, p. 194).

Estes autores garantem também que “[...] O desenvolvimento das capacidades perceptivas inibe ou incrementa significativamente a performance de movimento da criança [...]” de movimento da criança [...]” (GALLAHUE, OZMUN e GOODWAY, 2013, p. 297, grifo dos autores) e que, por isto, é indispensável ao educador ter uma perfeita compreensão de que o processo de percepção não é totalmente congênito e que, quanto melhores e mais frequentes forem as possibilidades de movimento viabilizadas para a criança, melhor será a evolução de suas capacidades perceptivas.

No início da infância a criança envolve-se com as duas atividades socioemocionais vitais voltadas ao crescimento do seu juízo de iniciativa e da autonomia expressas

[...] por um senso crescente de independência [...] é preciso dar a criança abundância de situações em que expressões de sua autonomia são razoáveis e apropriadas. [...] o senso de iniciativa em expansão é observado na curiosidade, exploração e comportamento muito ativo. As crianças engajam-se em novas experiências, como subir, pular, correr e jogar objetos por conta própria e pela pura diversão de sentir e descobrir o que são capazes de fazer (GALLAHUE, OZMUN e GOODWAY, 2013, p. 194).

Diante disto, entende-se que o desenvolvimento da autonomia e da iniciativa é fundamental para a criança construir sua essência e crescer afetivamente, pois suas funções afetivas participam do desenvolvimento das suas funções cognitivas e psicomotoras e ambas do aprimoramento das capacidades tempo-espacial.

Observa-se que o processo aquisitivo da autonomia é complexo e que ações voltadas para a promoção do aprimoramento perceptivo-motor estão diretamente relacionadas e que são dependentes do desenvolvimento organizado da habilidade espaçotemporal definida por Janssen (2015 apud FARIA e COSTA, 2016) como a aptidão de a pessoa localizar-se ou guiar-se num espaço definido tendo como ponto de referência algum objeto, ou outro ou no seu corpo. 
Conforme Monroe (2016, s.p), Lev Vygotsky que viveu entre os anos de 1896 e 1934 e dedicou-se a estudar a relação organismo-meio ambiente, comprovou a importância desta relação para o progresso dos processos superiores da mente humana correlacionadas às atividades da pessoa no tocante ao planejar ações e conceber consequências para uma decisão, entre outras atividades.

Vygotsky (1984 apud SMOLE, 2014, p. 124) assevera que pela linguagem assimilada dos símbolos a criança ao brincar embrenha-se no espaço de todas as ações sociocriativo-culturais e coloca-se frente a frente com problemas e desafios que a estimulam a utilizar o seu corpo, a raciocina, a descobrir, a persistir, a perseverar e a esforçar-se para buscar e encontrar soluções para resolvê-los.

Neste tópico evidencia-se o quão relevante é o processo de evolução das habilidades afetivas da criança que aprimoram suas capacidades psicomotoras e mentais que aperfeiçoam suas faculdades tempo-espacial. Comprova-se a relevância de estimular a criança ao empregar seu corpo e, através do brincar, das brincadeiras, dos brinquedos e dos jogos, relacionar-se com o outro, explorar, insistir e descobrir meios para solucionar novos desafios que surgirem.

\subsection{A importância da Psicomotricidade na Educação Infantil}

Através das obras pesquisadas nota-se a necessidade de abordar a importância da Psicomotricidade na EI para o desenvolvimento da criança. Conceitua-se, pois, Psicomotricidade destacando que o movimento da criança está diretamente vinculado à ação de brincar.

Fonseca (1993 apud AGUIAR, 2015) afirma que a Psicomotricidade é imprescindível à educação atual. Faria e Costa (2016, p. 6) a definem como "[...] a educação do/pelo movimento, atuando sobre o cognitivo" enquanto a ABP (2020, s.p) a considera como: "[...] a ciência que têm como objetivo de estudo o homem através do seu corpo em movimento e em relação ao seu mundo interno e externo".

Consoante Carvalho (2003) ela está dividida em dois grupos de intervenção: a terapêutica e a educativa. Segundo a ABP (2020) ela mantém relação com as áreas de 
educação e de reeducação terapêutica, relacional, aquática e ramain. Quando relacionada à intervenção terapêutica ela realiza a reeducação psicomotora e, quando relacionada ao âmbito educacional, facilita o desenvolvimento da criança em estágio pré-escolar de modo a “[...] trabalhar a criança e o grupo em movimento através da ação espontânea ou organizada a priori. Beneficia-se a integração de si em relação com o outro e ao meio em geral" (CARVALHO, 2003, p. 84-85).

Ainda sobre o campo educacional, Canto e Barbosa (2010) a caracterizam como uma ferramenta ou um método pedagógico ótimo para ensinar crianças pequenas em idade pré-escolar, pois através dela a criança excita tanto o corpo quanto a mente. Observam ainda, que a Educação Psicomotora vai além da preocupação com o saber escolar ou do aprimoramento da motricidade e afirmam que ela quando direcionada à educação deve visar à formação da personalidade da criança e ao aperfeiçoamento da sua expressividade e organização, por meio de atividades que abrangem o relacionamento, a realização e a criação. A Educação Psicomotora “[...] compreende a educação do ser humano nos seus aspectos corporais, motores, emocionais, intelectuais e sociais" (CARVALHO, 1996 apud CARVALHO, 2003, p. 85).

Lima (2016) defende que a psicomotricidade determina que o corpo tanto influencia quanto é influenciado pelo cérebro e pelo psiquismo e a ABP (2020), afirma-se que ela se relaciona com o processo de maturação que envolve o corpo como fator originador de aquisições cognitivas, afetivas e orgânicas, processo estes que são suportados por três conhecimentos básicos: o movimento, o intelecto e o afeto.

Diante do conteúdo exposto entende-se ter sido possível demonstrar que o movimento é essencial para o aprimoramento integral da criança na EI, objetivando introduzir o assunto a ser discorrido na próxima seção e reconhecendo que o movimento está intimamente relacionado à relação de brincar.

\subsection{A ludicidade na aprendizagem infantil vinculada à conceituação de jogo, brincadeira, brinquedo e lúdico}

A ludicidade ainda é um assunto pedagógico que ocupa posição de destaque nos debates, embora a ação de brincar e os jogos acompanhem o homem, desde os tempos mais 
distantes e muito contribuem para o conhecimento da criança, para a sua saúde física, emocional e mental (MAURÍCIO, 2008 apud FARIA e COSTA, 2016).

Neste contexto, destacam- se o brinquedo definido como toda ferramenta que a criança utiliza para a brincadeira, ao jogo e ao divertimento e, enquanto recurso vinculalhe os brinquedos e materiais usados para realizar ações lúdicas. A autora enfatiza que a ludicidade é uma ação essencial para a efetivação do aprimoramento infantil e alerta que ela não pode ser entendida apenas como um recurso pedagógico específico destinados às atividades escolares. Ela precisa ter uma significação mais ampla e vista desde a formação do professor à impecável preparação dos espaços e dos tempos escolares.

Dentre outros autores pesquisados ressalta-se que, embora existirem diversas correntes eu classificam o jogo conforme suas ideias, há um ponto de vista comum entre elas: a valor do jogo na EI e que, infelizmente, os estudos á realizados ainda não influenciaram categoricamente a elaboração do currículo escolar e que, por isto, as instituições escolares muito pouco o utilizam como ferramentas psicopedagógica, embora saibam que o jogo infantil quando devidamente aplicado à EI, favorece o ensino aprendizagem da criança.

Quanto à brincadeira, ela assume a função de promover o pensamento-ação infantil enquanto constituinte ativo da "[...] linguagem (gestual, falada ou escrita)" (ALMEIDA, 1995 apud AGUIAR, 2015, p. 20) e, no tempo-espaço da EI, ela conduz a criança à fantasia e permitindo-lhe compor uma grande "[...] parte de seus repertórios cognitivos, emocionais, sociais e motores" (AGUIAR, 2015, p. 25).

Por conta disto, Kishimoto (2013) assevera que escolas e educadores devam providenciar e ofertar espaços e momentos certos para a realizações de brincadeiras e, sobre os espaços, ela defende que os brinquedos devam estar disponíveis em sala de aula, além das habituais mesas e cadeiras.

Acerca da ludicidade, adverte-se que ela deve ser incluída na EI de tal forma que facilite a aprendizagem, possibilite à criança novos e atraentes modos de relacionar-se, interagir, comunicar-se com as outras crianças e adquirir conhecimentos (BRASIL, 2007). Deste modo, embora haja inúmeras formas de inserir a ludicidade na aprendizagem é importante entender que uma atividade pedagógica, para ser realmente lúdica, deve 
conduzir a criança à fruição, à decisão, à escolha, a novas descobertas, bem como permitirlhe questionar e encontrar respostas. Assim ao

[...] incorporarmos de forma mais efetiva a ludicidade nas nossas práticas, estaremos potencializando as possibilidades de aprender e o investimento e o prazer das crianças [...] no processo de conhecer. E, com certeza, descobriremos também novas formas de ensinar e de aprender com as crianças [...] (BRASIL, 2007, p, 43)

Realça-se que a ludicidade tem um potencial fabuloso para expandir e facilitar o processo ensino-aprendizagem da criança, pois, enquanto nela desperta o interesse, ao professor possibilita descobrir novas formas de ensiná-la e novos conteúdos e ensinar-lhe. Assim, para oportunizar estas perspectivas, pontua-se a necessidade de adotar atividades que envolvam jogos que articulem "[...] a linguagem imagética, a ação motora e a ludicidade" (BRASIL, 2007, p. 54).

Ademais, ressalta-se, segundo BRASIL (2013), que um planejamento bem elaborado que contemple todas as atividades educacionais e que sejam embasados em objetivos específicos beneficia a criança durante a constituição de todas as suas aptidões e a auxilia na aprendizagem do cuidar de si própria.

Com base nisso, as Diretrizes Curriculares Nacionais Gerais da Educação Básica (DCNGEB), através do artigo $6^{\circ}$ e $7^{\circ}$ fixam os princípios pedagógicos que devem ser respeitados obrigatoriamente na EI quanto à aplicação da ludicidade e à função sociopolítica e pedagógica da escola de EI.

Ratifica-se que o mencionado ato de ensinar a criança a cuidar de si não é o único objetivo da educação: “[...] Educar cuidando inclui acolher, garantir a segurança, mas também alimentar a curiosidade, a ludicidade e a expressividade infantis" (BRASIL, 2013, p. 89) e, segundo o RCNEI, que o “[...] cuidar significa valorizar e ajudar a desenvolver capacidades [e que] o cuidado é um ato em relação ao outro e a si próprio que possui uma dimensão expressiva e implica em procedimentos específicos” (BRASIL, 1998ª , p. 24)

Ainda sobre o cuidar da criança na EI trata-se de uma ação que requer a junção de vários saberes conexos e diversas áreas do conhecimento e a efetiva colaboração e profissionais capacitados que possam contribuir para o desenvolvimento integral da 
criança, considerando e reconhecendo sob conceituação mais amplas, que os cuidados devem abarcar tanto aqueles relacionados ao proteger, à saúde e a alimentação quanto às carências afetivas, de interação, integração e estímulo, bem como de segurança e de brincadeiras que permitam à criança realizar novas explorações e descobertas (BRASIL, 1998a).

Vale ressaltar, segundo Kishimoto (2013), que o professor da EI precisa mediar o aprendizado da criança, observar seu comportamento enquanto brinca, vem como identificar e disponibilizar para ela o que estiver faltando, pois, somente assim, por meio de uma ótima interação sinergética e simultânea dos materiais (estrutura), professor e mediação, é possível tornar o processo ensino-aprendizagem eficaz.

Acerca disto, ratifica-se a concepção Aguiar (2015) quanto à precisão de aplicar jogos como metodologia pedagógica para transmitir conceitos do dia a dia ao aluno.

\section{Considerações finais}

Acredita-se ter sido possível destacar neste tópico a necessidade de a ludicidade ser vista como uma poderosa ferramenta pedagógica que utiliza o brincar, os brinquedos e a brincadeira para facilitar o desenvolvimento integral da criança pela estimulação das suas capacidades motoras, mentais, emocionais, relacionais, criativas, de comunicação e de socialização, contudo, alerta-se que compete ao professor definir objetivos coerentes e, sobretudo, assegurar à criança a devida acolhida e segurança que ela tanto necessita.

\section{REFERÊNCIAS BIBLIOGRÁFICAS}

AGUIAR, J. S. de. Educação Inclusiva: jogos para o ensino de conceitos. Campinas, Papirus: 2015.

ALMEIDA, P. N. Educação Lúdica: técnicas e jogos pedagógicos. Rio de Janeiro: Loyola, 1998. In: AGUIAR, J. S. de. Educação Inclusiva: jogos para o ensino de conceitos. Campinas, Papirus: 2015

APPOLINÁRIO, F. Dicionário de metodologia científica: um guia para a produção do conhecimento científico. 2. Ed. São Paulo: Atlas, 201 r.

ASSOCIAÇÃO BRASILEIRA DE PSICOMETRIA (ABP). O que é Psicomotricidade. ABP. [S.I] 2020. Disponível em https://psicomotricidade.com.br/sobre/o-que-epsicomotricidade. Acesso em: Io mar. 2020. 
BARBOSA, C. B. B.; SILVEIRA, S. H. P.; OlIVEIRA, J. E. C. de. Psicomotricidade e desenvolvimento humano. Efdeportes, ano 19, n. 192, Buenos Aires, mai. 2014. In: FARIA, B. B.; COSTA, C. R. B. Educação Física e atividade Lúdica: O papel da ludicidade no desenvolvimento Infantil. Revista Científica Multidisciplinar Núcleo do Conhecimento. Ano I, v. 9. pp. 136-I55, out./nov., 2016. Disponível em: https://www.nucleodoconhecimento.com.br/educacao-fisica-e-atividade-ludica. Acesso em: 3 mar. 2020 .

BERNARDELLI, K. C. C. A. A Criança no ciclo de alfabetização: ludicidade nos espaços/tempos escolares. In: BRASIL. Pacto Nacional pela Alfabetização na Idade Certa: A criança no ciclo de alfabetização. Caderno o2. Brasília: MEC, SEB, 2015. Disponível em <http://pacto.mec.gov.br/images/pdf/Cadernos_2015/cadernos _novembro/pnaic_cad_2_19112015.pdf $>$. Acesso em 2 mar. 2020.

BRASIL. Lei 8.069, de 13 de julho de 1990. Estatuto da Criança e do Adolescente. Brasília, 1990. Disponível em: 〈http://www.planalto.gov.br/ccivil_03/leis/L8o69.htm〉. Acesso em: 2 mar. 2020.

Ministério da Educação e do Desporto. Secretaria de Educação Fundamental. Referencial Curricular Nacional para a Educação Infantil. MEC/SEF, Brasília: $\mathrm{MEC} / \mathrm{SEF}$, I998a. v. I. Disponível em: <http://portal.mec.gov.br/seb/arquivos/pdf/ rcnei_voli.pdf $>$. Acesso em: 2 mar. 2020.

- Ministério da Educação e do Desporto. Secretaria de Educação Fundamental.

Referencial Curricular Nacional para a Educação Infantil. __. Ministério da Educação e do Desporto. Secretaria de Educação Fundamental. Referencial Curricular Nacional para a Educação Infantil. MEC/SEF. Brasília, 1998c. v. 3. Disponível em: $\langle$ http://portal.mec.gov.br/seb/arquivos/pdf/ volume3.pdf $\rangle$. Acesso em: 2 mar. 2020.

Ministério da Educação. Secretaria de Educação Básica. Secretaria de Educação Continuada, Alfabetização, Diversidade e Inclusão. Secretaria de Educação Profissional e Tecnológica. Conselho Nacional da Educação. Câmara Nacional de Educação Básica. Diretrizes Curriculares Nacionais Gerais da Educação Básica (DCNs). Brasília: MEC, SEB, DICEI, 2013. Disponível em: 〈http://portal. mec.gov.br/ index.php?option=com_ docman\&view=download\&alias $=\quad$ 15548-d-c-n-educacao-basica-nova-pdf\&Itemid=30192 $>$. Acesso em: 3 mar. 2020.

CANTO, R. R.; BARBOSA, F. S. S. Psicomotricidade aplicada ao desenvolvimento do esquema corporal. Semana de Ciências e tecnologia de Ariquemes, v. I, n. I, 2010. Disponível em: 〈http://www.periodicos.unir.br/index.php/secta/article/view/63〉. Acesso em: 2I mar. 2020.

CARVAlHO, E. M. R. de. Tendências da Educação Psicomotora Sob o Enfoque Walloniano. Revista Psicologia Ciência e Profissão, 2003, 23 (3), p. 84-89. Disponível em: $\langle$ http://www.scielo.br/pdf/pcp/v23n3/v23n3ai2.pdf〉. Acesso em: 20 mar. 2020. 
v. 2. Disponível em: 〈http://portal.mec.gov.br/seb/arquivos/pdf/ volume2.pdf $\rangle$. Acesso em: 2 mar. 2020.

COUTINHO, Â. M. S. A ação social dos bebês: um estudo etnográfico no contexto da creche. Tese de Doutorado. Instituto de Educação. Universidade do Minho. Minho, Portugal 2oro. In: GUIMARAES, D.; ARENARI, R. Na creche, cuidados corporais, afetividade e dialogia. Educ. Rev., Belo Horizonte, v. 34, er86909, 2018. Disponível em: 〈http://www.scielo.br/scielo.php?script=sci_arttext\&pid=Soro2-4698201800o100155 \&lng=en\&nrm=iso $>$. Acesso em: 4 mar. 2020.

FARIA, B. B.; COSTA, C. R. B. Educação Física e atividade Lúdica: O papel da ludicidade no desenvolvimento Infantil. Revista Científica Multidisciplinar Núcleo do Conhecimento. Ano I, v. 9. pp. I36-155, out./nov., 2016. Disponível em: 〈https://www.nucleodoconhecimento.com.br/educacao/educacao-fisica-e-atividadeludica>. Acesso em: 3 mar. 2020.

FONSECA, V. Psicomotricidade. 3. ed. São Paulo: Martins Fontes, 1993. In: AGUIAR, J. S. de. Educação Inclusiva: jogos para o ensino de conceitos. Campinas, Papirus: 2015.

GAllahUE, D. L.; OZMUN, J. C.; GOODWAY, J. D. Compreendendo o desenvolvimento motor: bebês, crianças, adolescentes e adultos. Tradução: Denise Regina de Sales. 7. ed. Porto Alegre: AMGH, 2013.

GUIMARAES, D.; ARENARI, R. Na creche, cuidados corporais, afetividade e dialogia. Educ. Rev., Belo Horizonte, v. 34, er86909, 2018. Disponível em: 〈http://www.scielo.br/scielo.php?script=sci_arttext\&pid=Soro2-4698201800o10o155 $\& \operatorname{lng}=$ en $\&$ nrm=iso $>$. Acesso em: 4 mar. 2020.

INFÂNCIA. Dicio, Dicionário Online de Português, 2020. Disponível em: $\langle$ https://www.dicio.com.br/infancia/>. Acesso em: 3 mar. 2020.

KISHIMOTO, T. A Importância do Brincar. 24 abr. 2013. Entrevista concedida a Tatiana Bertoni. I2'56". Disponível em: 〈https://www.youtube.com/watch?v=oalıA_ UBdWA〉. Acesso em: 28 mar. 2020.

LIMA, E. de S. As contribuições da neuropedagogia no processo ensino e aprendizagem. In: III Congresso Nacional de Educação. 05 a 07 out. 2016. Natal. i2 p. In: FARIA, B. B.; COSTA, C. R. B. Educação Física e atividade Lúdica: O papel da ludicidade no desenvolvimento Infantil. Revista Científica Multidisciplinar Núcleo do Conhecimento. Ano I, v. 9. pp. I36-155, out./nov., 2016. Disponível em: 〈https://www.nucleodoconhecimento.com.br/educacao/educacao-fisica-e-atividadeludica>. Acesso em: 3 mar. 2020.

MARCONI, M. de A.; LAKATOS, E. M. Fundamentos de metodologia científica. 8. ed. [3. reimpr.]. São Paulo: Atlas, 2019. 
MAURÍCIO, J. T. Aprender brincando: o lúdico na aprendizagem. Psicopedagogia, 2008. Disponível em: <http://www.psicopedagogia.com.br/newi_opiniao.asp?entrID= 678\#.V9KZAlsrI2x>. In: FARIA, B. B.; COSTA, C. R. B. Educação Física e atividade Lúdica: $O$ papel da ludicidade no desenvolvimento Infantil. Revista Científica Multidisciplinar Núcleo do Conhecimento. Ano I, v. 9. pp. 136-155, out./nov., 2016. Disponível em: 〈https://www.nucleodoconhecimento.com.br/ educacao/educacao-fisicae-atividade-ludica $>$. Acesso em: 3 mar. 2020.

MONROE, C. Vygotsky e o conceito de aprendizagem mediada, 2016. Disponível em: <https://novaescola.org.br/conteudo/274/vygotsky-e-o-conceito-de-aprendizagemmediada $>$. Acesso em: io mar. 2020.

NEGRINE, A. Simbolismo e jogo. Petrópolis, RJ: Editora Vozes, 2014.

SMOLE, K. S. A matemática na educação infantil: a teoria das inteligências múltiplas na prática escolar. Porto Alegre: Penso, 2014.

VYGOTSKI, L. S. A formação social da mente. São Paulo: Martins Fontes, 1984. In: SMOLE, K. S. A matemática na educação infantil: a teoria das inteligências múltiplas na prática escolar. Porto Alegre: Penso, 2014. 